\title{
"Spontaneous" CSF Fistula due to Transtegmental Brain Herniation in Combination with Signs of Increased Intracranial Pressure and Petrous Bone Hyperpneumatization: An Illustrative Case Report
}

\author{
Diones Rivera ${ }^{1}$ Rafael Fermin-Delgado ${ }^{2}$ Peter Stoeter ${ }^{2}$ \\ ${ }^{1}$ Department of Neurosurgery, CEDIMAT, Plaza de la Salud, \\ Santo Domingo, Republica Dominicana \\ 2 Department of Radiology, CEDIMAT, Plaza de la Salud, \\ Santo Domingo, Republica Dominicana \\ Address for correspondence Peter Stoeter, MD, Department of \\ Radiology, CEDIMAT, Plaza de la Salud, Santo Domingo, Republica \\ Dominicana (e-mail: peter.stoeter@gmx.de).
}

J Neurol Surg Rep 2014;75:e251-e254.

\begin{abstract}
Background and Importance Transtegmental brain herniation into the petrous bone is a rare cause of rhinoliquorrhea. Our case presents a combination of several typical clinical and imaging findings illustrating the ongoing etiologic discussion of such cerebrospinal fluid (CSF) fistulas.

Clinical Presentation A 53-year-old man presented with nasal discharge after a strong effort to suppress coughing. Imaging revealed a transtegmental herniation of parts of the inferior temporal gyrus into the petrous bone and in addition a combination of signs of chronically increased intracranial pressure and a hyperpneumatization of the petrous bone. The fistula was closed by a middle cranial fossa approach.

Keywords

- CSF fistula

- brain herniation

- increased intracranial pressure

- petrous bone

Conclusion The case illustrates the two main predisposing factors for development of petrous bone CSF fistulas: increased intracranial pressure and thinning of the tegmental roof due to extensive development of air cells. Because the CSF leakage repair does not change the underlying cause, patients have to be informed about the possibility of developing increased intracranial pressure and recurrences of brain herniations at other sites.
\end{abstract}

\section{Introduction}

Transtegmental brain herniation is considered a rare cause of rhinoliquorrhea, although some small series of this entity have been published during recent years in the neuro-otologic and neurosurgical literature. ${ }^{1-4}$ After early speculations about some congenital origin as embryogenic faults in the dura mater and adjacent tegmen, ${ }^{5}$ other causes are favored at present because the herniations appeared later in life, and there are some hints about increased intracranial pressure (IIP) and hyperpneumatization of the petrous bone as contributing factors.

received

November 11, 2013

accepted after revision

June 9, 2014

published online

November 12, 2014
DOI http://dx.doi.org/ 10.1055/s-0034-1387183. ISSN 2193-6358.
In this respect, our case shows a combination of several typical clinical and imaging findings illustrating the ongoing etiologic discussion about brain herniation in the middle cranial fossa.

\section{Case Report}

Some days after a concerted and ultimately unsuccessful effort to suppress coughing and not disturb his sleeping wife, a 54-year-old man experienced a nasal discharge that was characterized as cerebrospinal fluid (CSF) by laboratory examination. There were no further complaints except for
License terms

Stuttgart · New York

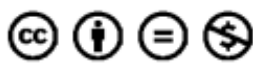



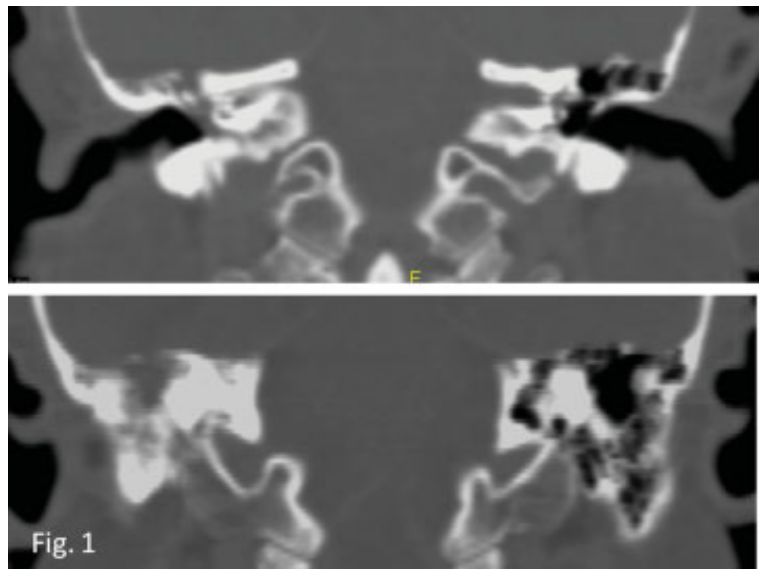

Fig. 1 Computed tomography image of temporal bone, coronal reconstruction, at the level of the cavum tympani (upper image) and the mastoid (lower image). Defect in the right tegmen and opacification of the cavum and adjacent air cells. Extensive pneumatization of the contralateral petrous bone and thinning of its tegmental plate.

occasional headaches and some "numbness" of his right ear, and neurologic and other clinical findings were normal. In particular, there were no signs of visual disturbances, hormonal deficiencies, or convulsions.

Nine months later, computed tomography (CT) ( - Fig. $\mathbf{1})$ imaging revealed a collection of soft tissue and fluid in the right cavum tympani and pyramidal air cells together with a bony defect of the anterior part of the tegmen, whereas the left petrous bone presented as hyperpneumatized together with an obvious thinning of the tegmental plate.

In magnetic resonance (MR) imaging( - Fig. 2-4), the soft tissue was identified as a herniation of the lateral inferior gyrus of the temporal lobe into the petrous bone together with an accompanying focal gliosis and widening of the temporal horn, but without alterations of the hippocampus. In addition, we saw an enlargement of the supratentorial part of the ventricular system together with a stenotic aqueduct and a partial destruction of the septum pellucidum, an "empty" sella, a moderately enlarged prepontine cistern, and slightly enlarged subdural spaces around both optic nerves that altogether were interpreted as signs of chronically IIP.

The patient was operated on using a subtemporal middle cranial fossa approach. The herniated parts were resected,

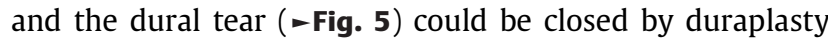
using a temporal muscle implant. To avoid complications in the absence of evident clinical signs of the IIP, we decided not to apply any shunting or ventriculostomy but to follow the course closely. For 3 months, the patient has been free of symptoms without any further nasal discharge or enlargement of the ventricles on CT.

\section{Discussion}

Because of the close temporal relations, the final origin of the transtegmental herniation of the inferior temporal gyrus into the petrous bone can be attributed to a forced coughing suppression effort that usually accompanies a sudden rise of intracranial pressure in the sense of a Valsalva maneuver. In this sense, our classification of the fistula as a "spontaneous" one appears to be justified.

More interesting than its classification is the discussion of predisposing factors because without a doubt, the development of such herniations and fistulas after coughing remains an unusual event. Just recently, the close relationship between spontaneous CSF fistulas and IIP was pointed out in the ophthalmic literature ${ }^{6}$ because of $(1)$ similar demographics of the patients' cohort showing a high body mass index, ${ }^{7,8}(2)$ development of IIP after closure of these fistulas, ${ }^{6}$ and (3) a higher recurrence rate of CSF fistulas in patients with IIP that may require ventriculoperitoneal shunting. ${ }^{9}$

In our case, MR imaging revealed various signs of chronically IIP within the ventricular system (enlarged ventricles proximal to the stenosed aqueduct including a bulging of the floor of the third ventricle) and within the subdural and
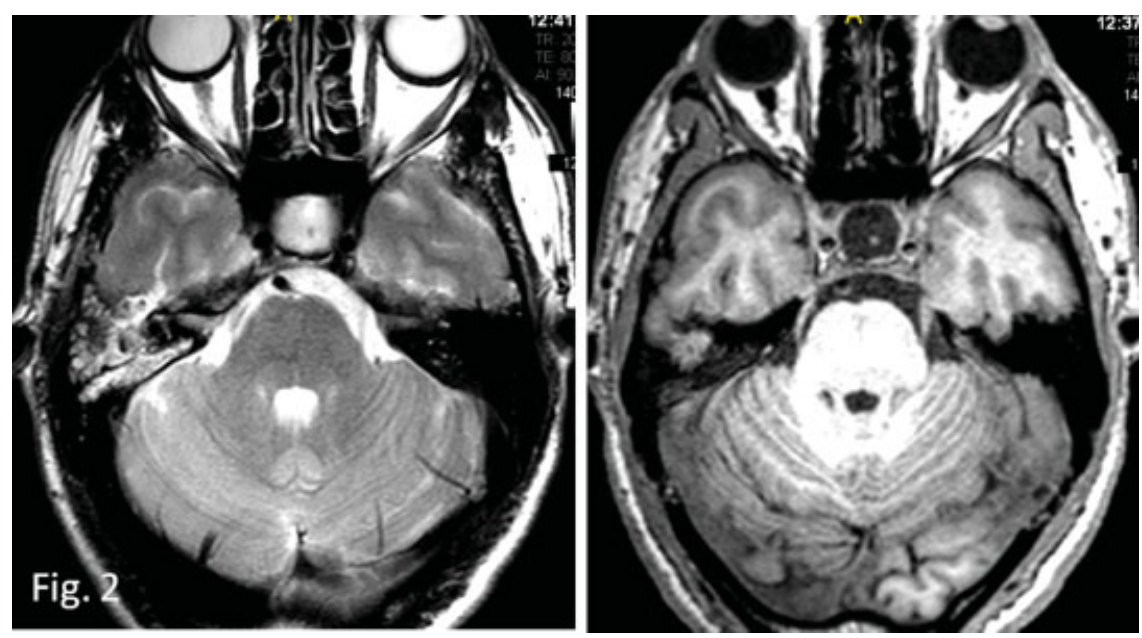

Fig. 2 Magnetic resonance imaging of the middle and posterior cranial fossa, transversal sections, T1-weighted (right image) and T2-weighted (left image). Transtegmental herniation of the inferior temporal gyrus, opacification of the adjacent air cells, and "empty sella." 

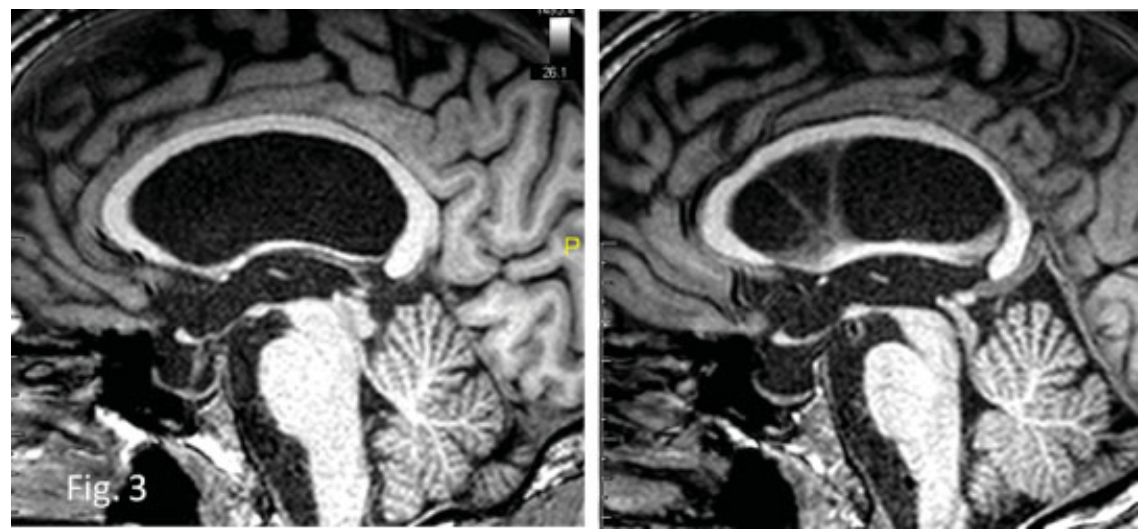

Fig. 3 Magnetic resonance imaging of midline structures, paramedian sections, T1-weighted. Enlargement of third ventricle with bulging of ventricular floor, "empty sella," enlargement of prepontine cistern, and extensive defects of the septum pellucidum.

subarachnoid space as the "empty" sella sign, an enlarged prepontine cistern, and a distension of the perioptic nerve sheaths. ${ }^{10-12}$ The extensive defects in the septum pellucidum also might be due to a secondary destruction as it has been described in other cases of aqueductal stenosis, but also in porencephaly and Chiari type 2 malformations. ${ }^{13}$ Although a maldevelopmental genesis cannot be ruled out completely, other signs of septo-optic dysplasia or involvement of the
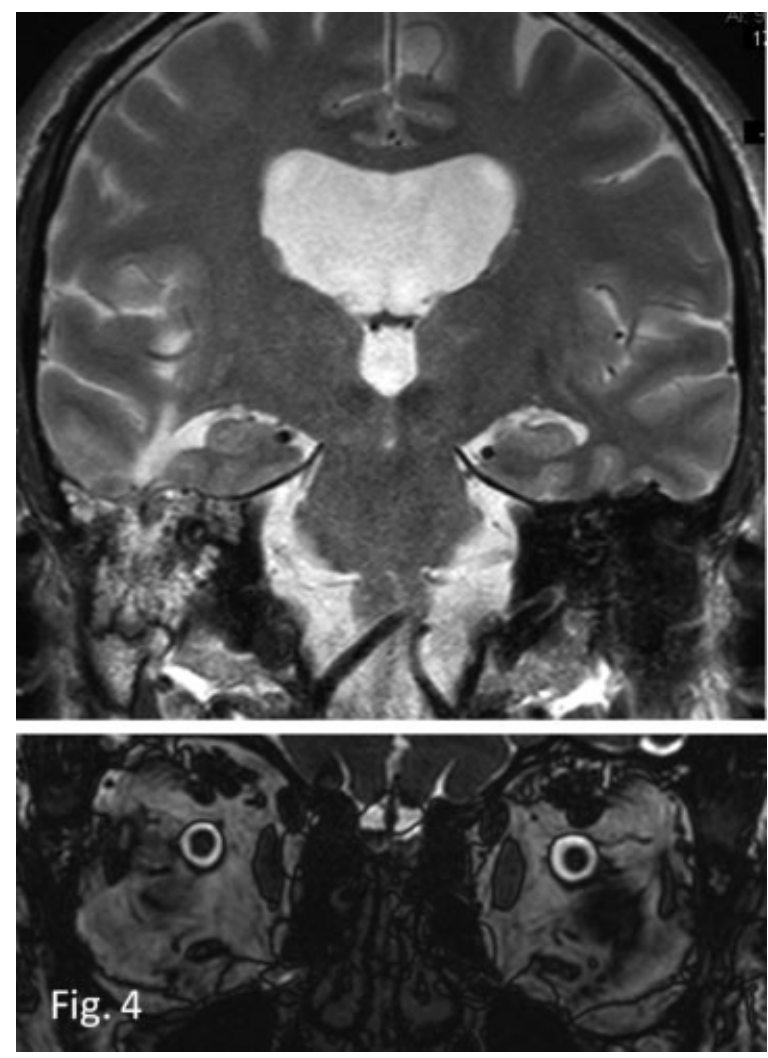

Fig. 4 Magnetic resonance (MR) at the level of the petrous bone (upper image) and orbita (lower image), T2 weighted. Transtegmental herniation, dilatation of right temporal horn and adjacent, increase in signal of temporal white matter indicating focal gliosis. Dilatation of lateral and third ventricle and (partial) destruction of septum pellucidum. Distension of cerebrospinal fluid space around the optic nerve. corpus callosum or the limbic system were not present, and isolated septal agenesis is extremely rare. ${ }^{14,15}$

Together with IIP, increased amplitudes of pulsatile CSF pressure waves are responsible for scalloping of the floor of the middle cranial fossa, mainly the anterior aspect of the petrous bone. This might explain why the anterior part of the pyramids is more susceptible to the development of fistulas and herniations as compared with the posterior side, ${ }^{16}$ and bilateral cases have been reported. ${ }^{17}$ The higher frequency of aberrant arachnoid granulations on the anterior part of the tegmen may be another reason for the uneven distribution of herniations between the anterior and posterior face of the petrous bone. ${ }^{18}$

A second predisposing factor may be seen in the vast amount of air cells occupying the lateral parts of the petrous bone in our case because hyperpneumatization has been described as a risk factor for the development of CSF fistulas after retrosigmoidal removal of a vestibular schwannoma. ${ }^{19}$ Hyperpneumatization usually goes together with a thinning

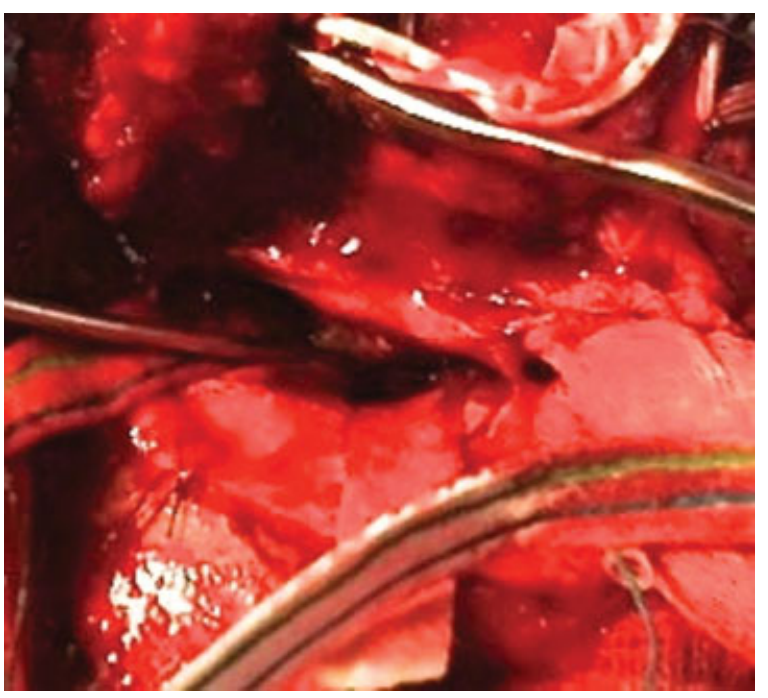

Fig. 5 Intraoperative situs after craniotomy showing a sonde passing from the middle cranial fossa through the dural tear into the cavum tympani. 
of the tegmental plate and thus decreases the resistance of the floor of the middle cranial fossa to chronic pressure wave erosions. In a similar sense, incomplete chondral ossification of specific parts of the tegmental plate has been proposed to increase the risk for development of herniations and fistulas. ${ }^{20}$

The treatment of herniations and CSF fistulas of the petrous bone is usually done by surgery, through a transmastoid approach, ${ }^{21,22}$ a middle cranial fossa approach, ${ }^{23}$ or a combination of both, sometimes after application of transient CSF drainage. They all show a high success rate of permanent closure. ${ }^{9}$ In our case, a subtemporal approach was chosen in order not only to repair the dural defect but also to preserve as much from the herniated temporal brain tissue as possible. However, some gliotic scarring in the laterobasal aspect of the temporal lobe was present before the operation, and this finally may turn out to be epileptogenic. ${ }^{24,25}$

\section{Conclusion}

The case reported here presents the rather rare finding of a transpetrosal CSF fistula due to brain herniation, and it illustrates the two main predisposing factors: chronically IIP and a thinning of the tegmental plate. Because the operative repair of the fistula does not eliminate these factors, further potential sites of fistula development at the floor of the anterior and middle cranial fossa have to be explored by imaging, and in addition, patients have to be informed about symptoms of IIP that may develop after closure of CSF leaks.

\section{References}

1 Brown NE, Grundfast KM, Jabre A, Megerian CA, O’Malley BW Jr, Rosenberg SI. Diagnosis and management of spontaneous cerebrospinal fluid-middle ear effusion and otorrhea. Laryngoscope 2004;114(5):800-805

2 Lim ZM, Friedland PL, Boeddinghaus R, Thompson A, Rodrigues SJ, Atlas M. Otitic meningitis, superior semicircular canal dehiscence, and encephalocele: a case series. Otol Neurotol 2012;33(4): 610-612

3 Sdano MT, Pensak ML. Temporal bone encephaloceles. Curr Opin Otolaryngol Head Neck Surg 2005;13(5):287-289

4 Wind JJ, Caputy AJ, Roberti F. Spontaneous encephaloceles of the temporal lobe. Neurosurg Focus 2008;25(6):E11

5 Schuknecht HF. Spontaneous cerebrospinal fluid fistula in the tegmen tympani . [in German]. HNO 1994;42(5):288-293

6 Pérez MA, Bialer OY, Bruce BB, Newman NJ, Biousse V. Primary spontaneous cerebrospinal fluid leaks and idiopathic intracranial hypertension. J Neuroophthalmol 2013;33(4):330-337

7 Goddard JC, Meyer T, Nguyen S, Lambert PR. New considerations in the cause of spontaneous cerebrospinal fluid otorrhea. Otol Neurotol 2010;31(6):940-945
8 Wang EW, Vandergrift WA III, Schlosser RJ. Spontaneous CSF leaks. Otolaryngol Clin North Am 2011;44(4):845-856, vii

9 Kenning TJ, Willcox TO, Artz GJ, Schiffmacher P, Farrell CJ, Evans JJ. Surgical management of temporal meningoencephaloceles, cerebrospinal fluid leaks, and intracranial hypertension: treatment paradigm and outcomes. Neurosurg Focus 2012;32(6):E6

10 Degnan AJ, Levy LM. Pseudotumor cerebri: brief review of clinical syndrome and imaging findings. AJNR Am J Neuroradiol 2011; 32(11):1986-1993

11 Hingwala DR, Kesavadas C, Thomas B, Kapilamoorthy TR, Sarma PS. Imaging signs in idiopathic intracranial hypertension: are these signs seen in secondary intracranial hypertension too? Ann Indian Acad Neurol 2013;16(2):229-233

12 Hoffmann J, Schmidt C, Kunte H, et al. Volumetric assessment of optic nerve sheath and hypophysis in idiopathic intracranial hypertension. AJNR Am J Neuroradiol 2014;35(3):513-518

13 Li Y, Sansgiri RK, Estroff JA, et al. Outcome of fetuses with cerebral ventriculomegaly and septum pellucidum leaflet abnormalities. AJR Am J Roentgenol 2011;196(1):W83-W92

14 Barkovich AJ, Norman D. Absence of the septum pellucidum: a useful sign in the diagnosis of congenital brain malformations. AJR Am J Roentgenol 1989;152(2):353-360

15 Supprian T, Sian J, Heils A, Hofmann E, Warmuth-Metz M, Solymosi L. Isolated absence of the septum pellucidum. Neuroradiology 1999;41(8):563-566

16 Nadaraja GS, Monfared A, Jackler RK. Spontaneous cerebrospinal fluid leak through the posterior aspect of the petrous bone. J Neurol Surg B Skull Base 2012;73(1):71-75

17 Lorente Muñoz A, Lisbona Alquézar MP, González Martínez L, Sevil Navarro J, Llorente Arenas EM. Atypical etiology of rhinorrhea: spontaneous bilateral temporal encephalocele. [in Spanish]. Acta Otorrinolaringol Esp 2012;63(3):237-240

18 Yew M, Dubbs B, Tong O, et al. Arachnoid granulations of the temporal bone: a histologic study of dural and osseous penetration. Otol Neurotol 2011;32(4):602-609

19 Stieglitz LH, Giordano M, Gerganov V, et al. Petrous bone pneumatization is a risk factor for cerebrospinal fluid fistula following vestibular schwannoma surgery. Neurosurgery 2010;67 (2, Suppl Operative):509-515

20 Tóth M, Helling K, Baksa G, Mann W. Localization of congenital tegmen tympani defects. Otol Neurotol 2007;28(8):1120-1123

21 Oliaei S, Mahboubi H, Djalilian HR. Transmastoid approach to temporal bone cerebrospinal fluid leaks. Am J Otolaryngol 2012; 33(5):556-561

22 Pelosi S, Bederson JB, Smouha EE. Cerebrospinal fluid leaks of temporal bone origin: selection of surgical approach. Skull Base 2010;20(4):253-259

23 Kutz JW Jr, Husain IA, Isaacson B, Roland PS. Management of spontaneous cerebrospinal fluid otorrhea. Laryngoscope 2008; 118(12):2195-2199

24 Aquilina K, Clarke DF, Wheless JW, Boop FA. Microencephaloceles: another dual pathology of intractable temporal lobe epilepsy in childhood. J Neurosurg Pediatr 2010;5(4):360-364

25 Byrne RW, Smith AP, Roh D, Kanner A. Occult middle fossa encephaloceles in patients with temporal lobe epilepsy. World Neurosurg 2010;73(5):541-546 